\title{
A longitudinal three-center study of craniofacial morphology at 6 and 12 years of age in patients with complete bilateral cleft lip and palate
}

\author{
Theodosia Bartzela • Christos Katsaros • Elisabeth Rønning • Sara Rizell • \\ Gunvor Semb • Ewald Bronkhorst • Demetrios Halazonetis • \\ Anne Marie Kuijpers-Jagtman
}

Received: 9 January 2011 / Accepted: 7 September 2011 / Published online: 24 September 2011

(C) The Author(s) 2011. This article is published with open access at Springerlink.com

\begin{abstract}
In this longitudinal study, the craniofacial morphology and evaluated soft tissue profile changes, at 6 and 12 years of age in patients with complete bilateral cleft lip and palate (CBCLP) were compared. Lateral cephalograms from 148 patients with CBCLP, treated consecutively at three European cleft centers, Gothenburg $\left(n_{\mathrm{A}}=37\right)$, Nijmegen $\left(n_{\mathrm{B}}=26\right)$, and Oslo $\left(n_{\mathrm{C}}=85\right)$, were evaluated. Eighteen hard tissue and ten soft tissue landmarks were digitized. Paired $t$ test, Pearson's correlation coefficients, and multiple regression models were applied for statistical analysis. ANOVA and Tukey-B, as a post hoc test, were used to evaluate the increments and compare centers. Hard and soft
\end{abstract}

T. Bartzela $\cdot$ A. M. Kuijpers-Jagtman $(\bowtie)$

Department of Orthodontics and Craniofacial Biology,

Cleft Palate Craniofacial Unit,

Radboud University Nijmegen Medical Centre,

309 Dentistry, P.O. Box 9101, 6500 HB Nijmegen,

The Netherlands

e-mail: orthodontics@dent.umcn.nl

C. Katsaros

Department of Orthodontics and Dentofacial Orthopedics,

University of Bern,

Freiburg str. 7,

3010 Bern, Switzerland

E. Bronkhorst

Department of Cardiology and Preventive Dentistry,

Radboud University Nijmegen Medical Centre,

309 Dentistry, P.O. Box 9101, 6500 HB Nijmegen,

The Netherlands

E. Rønning $\cdot$ G. Semb

Oslo University Hospital,

Department of Maxillofacial Surgery and Hospital Dentistry,

P.O. Box 4950, 0424 Oslo, Norway tissue data were superimposed using the generalized Procrustes analysis. For Nijmegen, the increments of the variables SNA, ANB, SN-NL, SN-ML, NL-ML, Snss, and Snpg were significantly different than the two other centers $(p=0.041$ to $<0.001)$. SNPg increments were significantly different between Nijmegen and Oslo $(p=0.002)$. The three cleft centers followed different treatment protocols, but the main differences in craniofacial morphology until 12 years of age were the growth pattern and the maxillary and upper incisor variables. Follow-up of these patients until facial growth has ceased, which may elucidate components for improving treatment outcome.

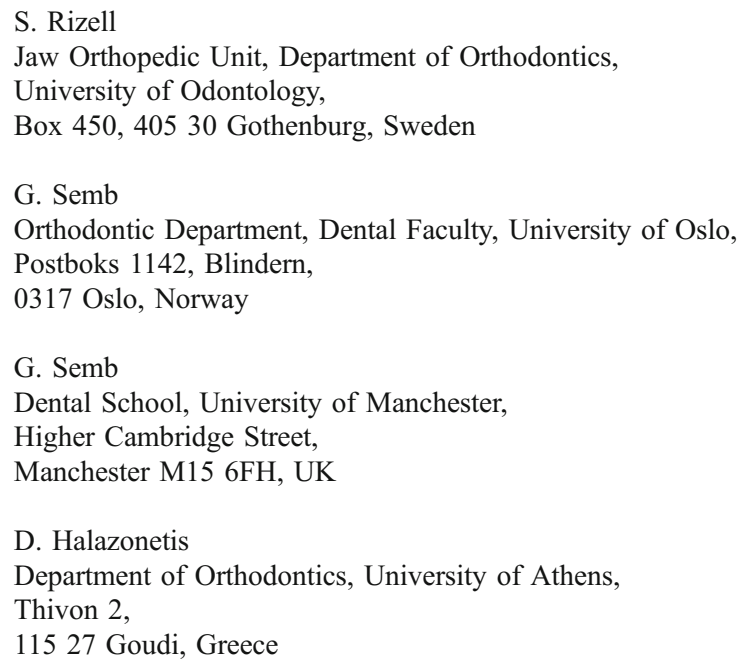


Keywords Bilateral cleft lip and palate $\cdot$ Craniofacial morphology Cephalometry . Treatment outcome .

Intercenter study

\section{Introduction}

Patients with a complete bilateral cleft lip and palate (CBCLP) are a challenge for the team involved in the interdisciplinary treatment of the condition. Longitudinal data on treatment outcome in patients with BCLP are scarce, probably due to the low incidence of the malformation [1]. Consequently, the scientific basis of the field is still weak, and hardly any evidence is available for current practices in surgery or orthodontics. Table 1 provides an overview of longitudinal studies on the craniofacial morphology of CBCLP from 6 to 12 years of age. To the best of our knowledge, only three studies have provided longitudinal data in this age range. One study [2] compared the outcome of the craniofacial treatment of CBCLP to craniofacial growth in non-cleft controls. In a Japanese study, the interest focused on specific surgical procedures, particularly one-stage versus two-stage palatoplasty [3]. In only one study, the craniofacial development of CBCLP until craniofacial growth ceased was compared between cleft centers in Oslo (Norway) and Nijmegen (the Netherlands) [4]. In addition to the few longitudinal studies, another worth mentioning is the largest mixed longitudinal data set on CBCLP to date, from the Cleft Palate Centre in Oslo (Norway), and presents facial growth from 5 to 18 or more years. The data set was compared to complete unilateral cleft lip and palate (CUCLP) patients treated in the same center [5].

In contrast to single-center studies, multicenter studies offer the possibility to collect a larger study sample, which offers the opportunity to compare different treatment protocols. Differences in the surgical and orthodontic procedures may indicate an inhibitory effect on the growth of the maxillary complex and a further result on the final treatment outcome. Following up patient samples longitudinally may identify the age at which growth starts to deviate between centers and may identify treatment procedures responsible. Therefore, the aim of the present study was to compare and longitudinally evaluate facial growth in patients with CBCLP at 6 and 12 years of age who were consecutively treated at three European cleft centers with different protocols.

\section{Patients and methods}

Patients selection

Three cleft centers participated in this study: Gothenburg, Sweden (center A); Nijmegen, the Netherlands (center B);

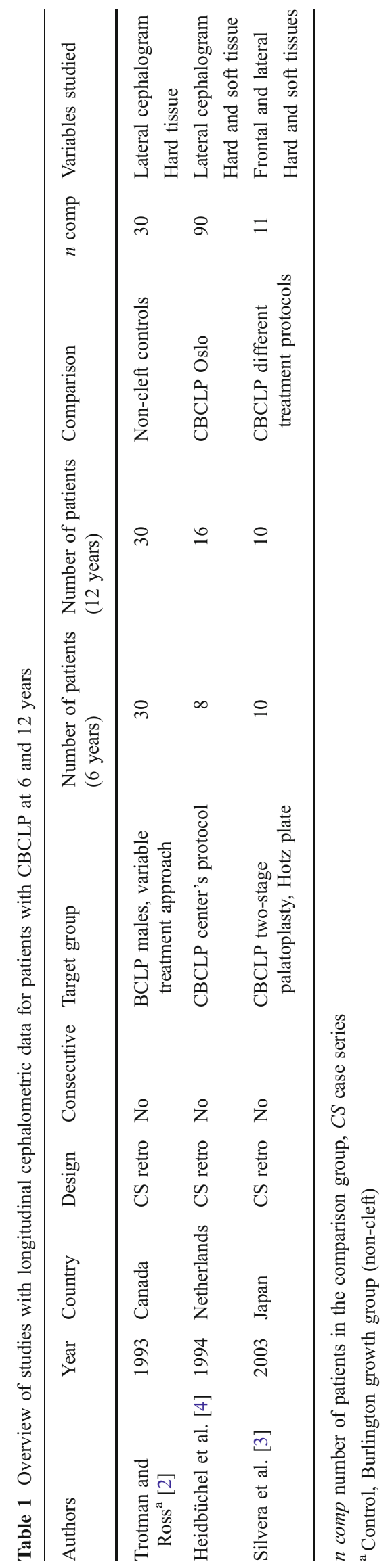


and Oslo, Norway (center C). Lateral cephalograms for 148 consecutively treated patients with CBCLP (Gothenburg, $n_{\mathrm{A}}=37$, born between 1965 and 1995 ; Nijmegen, $n_{\mathrm{B}}=26$, born between 1975 and 1995; and Oslo, $n_{\mathrm{C}}=85$, born between 1974 and 1995) at approximately 6 and 12 years of age were evaluated longitudinally.

The inclusion criteria were Caucasian ethnic background; no associated congenital malformations, syndromes, or mental retardation; treatment from birth onwards in the same center; cephalograms available in the age range of 5 to 7 and 11 to 13 years of age; and at least 12 years of age at the time of evaluation (born before 1996). In addition, all patients had complete BCLP with a diagnosis confirmed by the pre-operative written records, neonatal pictures of the face, and/or casts taken preoperatively. Patients with Simonart's band(s) were included only if no hard tissue union was present and the side of the Simonart's band was noted.

\section{Treatment protocols}

Table 2 shows the treatment protocols of the three centers. In the Gothenburg center, two surgeons were involved in the primary surgical procedures, in Nijmegen three, and in Oslo two. One basic difference among the centers is that Oslo does not employ infant orthopedics, whereas Nijmegen, and at that time Gothenburg, applied different infant orthopedic techniques. The surgical concepts of the lip closure procedure are also different among the centers; a one-stage procedure is performed at Nijmegen, whereas the other two centers finalize the lip closure in two operations. Soft palate closure varied among the centers between 6 and 18 months of age. The surgical soft palate closure technique is comparable in Nijmegen and Oslo, whereas Gothenburg has developed its own technique. Another important difference among the centers is early versus late hard palate closure. Oslo completes the hard palate closure between the ages of 3 and 6 months in two separate surgical procedures. In Gothenburg and Nijmegen, the hard palate is closed at a later stage, at approximately 9 years of age. In Nijmegen this is combined with a premaxillary osteotomy at roughly 9 years of age. Secondary procedures are performed in all centers, mainly consisting of columellaplasty at 6 to 7 years of age (Nijmegen and Oslo) and lip/nose revisions from the age of 6 years (all centers).

\section{Radiographic assessment}

Lateral cephalograms were available that had been taken in centric occlusion and oriented to the Frankfurt horizontal plane. The cephalograms from all centers were scanned on a 12-bit scanner (R2 ImageChecker M5000 DM, R2 Technology, Inc., Sunnyvale, CA, USA) at 150 dpi. For the cephalometric analysis, all cephalograms were digitized with a commercially available software program (Viewbox 3/dHAL Software, Kifissia, Greece) by one operator (TB) blinded to the center at which the patient was treated.

Table 2 Treatment protocols (primary procedures for lip, alveolus, and palate) for patients with complete bilateral cleft lip and palate from birth until 12 years of age at the cleft palate centers in this study

\begin{tabular}{|c|c|c|c|}
\hline Timing & Center $\mathrm{A}^{\mathrm{a}}$ & Center $\mathrm{B}^{\mathrm{b}}$ & Center $\mathrm{C}^{\mathrm{c}}$ \\
\hline Birth & $\begin{array}{l}\text { Infant orthopedics (duration, } 1.5 \text { years) } \\
\text { Nose plugs (duration, } 2.5 \text { years) }\end{array}$ & $\begin{array}{l}\text { Infant orthopedics with extra-oral strapping } \\
\text { (mean duration, } 9.2 \text { months) }\end{array}$ & \\
\hline 3 months & Bilateral lip adhesion (mean age, 3.3 months) & & $\begin{array}{l}\text { Straight-line lip closure and hard } \\
\text { palate closure on one side (mean } \\
\text { age, } 3.4 \text { months) }\end{array}$ \\
\hline 6 months & $\begin{array}{l}\text { Soft palate closure (center's own technique; } \\
\text { mean age, } 8.5 \text { months) }\end{array}$ & $\begin{array}{l}\text { One-stage lip closure (modified } \\
\text { Manchester; mean age, } 7.2 \text { months) }\end{array}$ & $\begin{array}{l}\text { Straight-line lip closure and hard } \\
\text { palate closure on the other side } \\
\text { (mean age, } 4.9 \text { months) }\end{array}$ \\
\hline 12 months & & $\begin{array}{l}\text { Modified Von Langenbeck soft palate } \\
\text { closure (mean age, } 13.8 \text { months) }\end{array}$ & \\
\hline 18 months & $\begin{array}{l}\text { Definitive bilateral lip and nose repair (mean } \\
\text { age, } 18 \text { months; center's own technique) }\end{array}$ & & $\begin{array}{l}\text { Modified von Langenbeck soft palate } \\
\text { closure (mean age, } 19 \text { months) }\end{array}$ \\
\hline 9 years & $\begin{array}{l}\text { One-side alveolar bone grafting (tibia) } \\
\text { (mean age, } 8.0 \text { years) } \\
\text { Hard palate closure with alveolar bone } \\
\text { grafting of second side (mean age, } \\
8.5 \text { years) }\end{array}$ & $\begin{array}{l}\text { Hard palate closure and bilateral alveolar } \\
\text { bone grafting (chin) (after 1975) } \\
\text { and osteotomy of the premaxilla } \\
\text { (mean age, } 9.9 \text { years) }\end{array}$ & $\begin{array}{l}\text { Bilateral alveolar bone grafting } \\
\text { (iliac crest) (mean age, } 9.9 \text { years) }\end{array}$ \\
\hline
\end{tabular}


Figure 1 shows the cephalometric reference points (18 hard and ten soft tissue landmarks) used in this study. Twenty cephalometric variables were calculated from these landmarks. Only angular measurements were used in order to avoid errors due to magnification differences between the centers. To determine the measurement error, 20 cephalograms for age 6 and 20 cephalograms for age 12 were randomly selected and digitized twice by the same operator (TB) at an interval of 1 month.

The generalized Procrustes analysis was used to superimpose the tracings in order to visualize the craniofacial morphology of patients at each center. This analysis was based on minimizing the square distances between corresponding points and scaling all tracings to a common

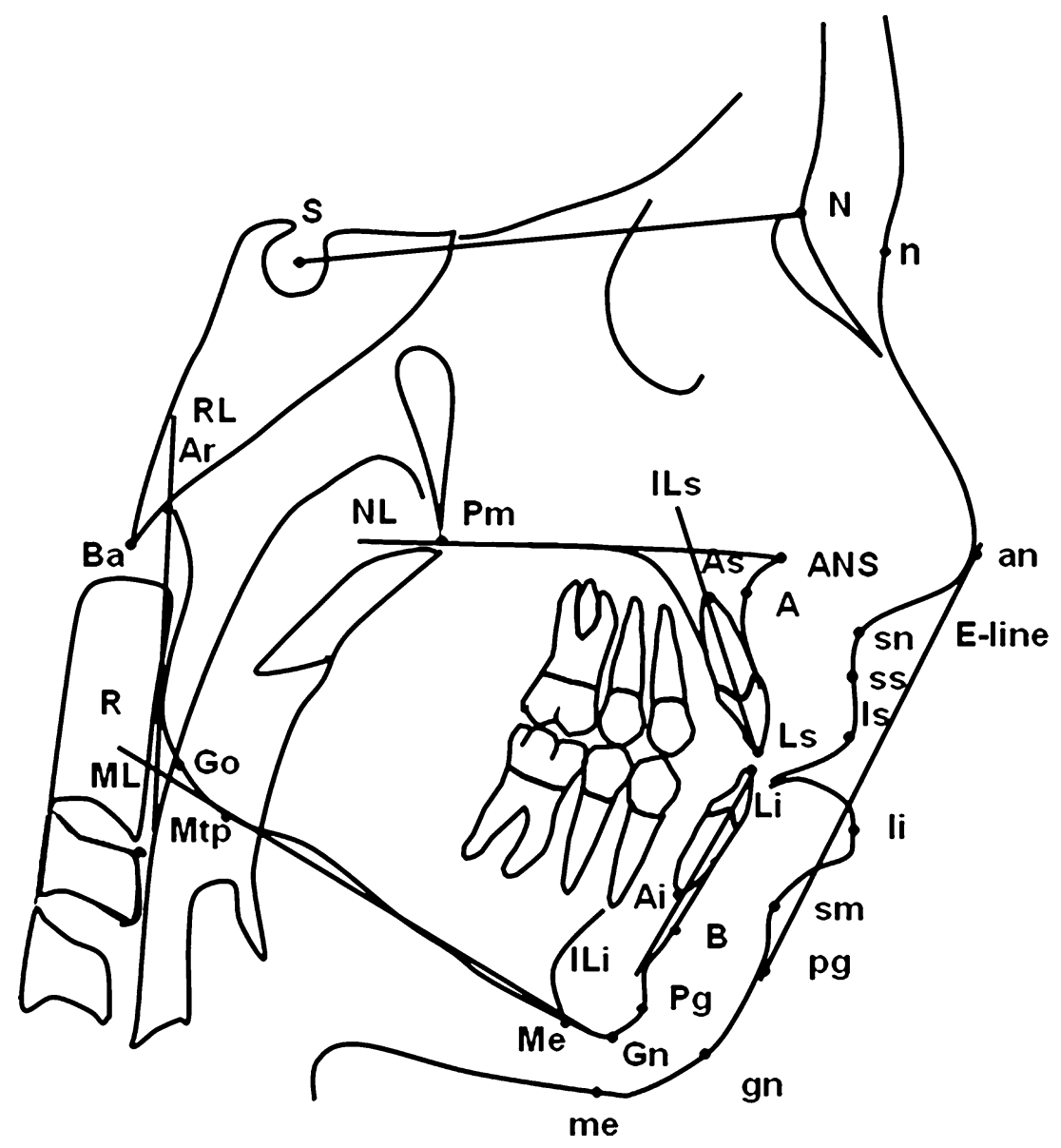

Fig. 1 Reference points on the lateral cephalometric radiographs. Skeletal reference points: $S$ sella-the geometric center of the sella turcica, $N$ nasion - the most anterior point at the frontonasial suture, $A N S$ anterior nasal spine, $A$ the deepest point on the anterior contour of the upper alveolar process, As apex superius - the apex of the root of the upper central incisor, $L s$ incision superius - the incisal edge of the most prominent upper incisor, $L i$ incision inferius - the incisal edge of the most prominent lower incisor, $A i$ apex inferius - the apex of the root of lower central incisor, $B$ the deepest point of the anterior contour of the lower alveolar process, $P g$ pogonion - the most anterior point of the mandibular symphysis. $G n$ gnathion-the most anterior inferior point of the bonny chin, Me menton - the most inferior point of the mandibular symphysis, Go gonion point - the most posterior inferior point on the angle of the mandible, Mtp mandibular tangent posterior - the most posterior inferior point on the outline of the mandibular body, $R$ ramus point - the most posterior-inferior point of the mandibular ramus, $\mathrm{Ar}$ articulare - the constructed point at the intersection of the images of the posterior margin of the ramus and the outer margin of the cranial base, $B a$ basion - the lowest point on the anterior margin of the foramen magnum in the median plane, $\mathrm{Pm}$ pterygo-maxillare - the intersection of the nasal floor and the apex of the pterygomaxillary fissure. Soft tissue reference points: $n$ soft tissue nasion - the deepest point on the frontonasal curvature, an anterior nasalis - the most prominent point on the nose tip, sn soft tissue subnasale - the point of intersection between the base of the nose and upper lip of soft tissue, ss soft tissue subspinale - the point of greatest concavity in the midline of the upper lip, $l s$ labrale superius - the most prominent point of the upper lip, $l i$ labrale inferius - the most prominent point of the lower lip, sm soft tissue supramentale - the point of the greatest concavity in the midline of the lower lip, pg soft tissue pogonion - the most prominent point on the soft tissue of the chin, gn soft tissue gnathion - the most anterior inferior point of the soft tissue chin, me soft tissue menton - the lowest point on the lower border of the mandible. Reference lines: $S N$ sella-nasion line, $N L$ nasal line - through Pm and ANS, ILs axis of upper incisors, ILi axis of lower incisors, $M L$ mandibular line - the tangent of the lower border of the mandible through Me and Mtp, $R L$ ramus line - through $\mathrm{Ar}$ and $\mathrm{R}$, E-line esthetic line - through an and pg. Hard tissue angles: SNA, SNB, ANB, SNPg, ILs-NL, ILs-SN, ILi-ML, ILs-ILi interincisal angle, SN-NL, SN-ML, NL-ML, RL-ML gonial angle, and NSBa. Soft tissue angles: S-n-an, S-n-ss, S-n-sm, S-n-pg, n-an-pg, ansn-ls nasolabial angle, and n-sn-pg 
Table 3 Characteristics of the centers at which the cephalograms were taken

$N$ number of patients per center, $S D$ standard deviation

${ }^{\mathrm{a}}$ Gothenburg

${ }^{\mathrm{b}}$ Nijmegen

${ }^{\mathrm{c}}$ Oslo

\begin{tabular}{|c|c|c|c|c|c|}
\hline & & & & 6-year group & 12-year group \\
\hline & $N$ & Male & Female & Mean age \pm SD & Mean age \pm SD \\
\hline Center $\mathrm{A}^{\mathrm{a}}$ & 37 & 26 & 11 & $6.8 \pm 0.59$ & $12.9 \pm 0.35$ \\
\hline Center $\mathrm{B}^{\mathrm{b}}$ & 26 & 21 & 5 & $6.1 \pm 0.34$ & $12.2 \pm 0.64$ \\
\hline Center $C^{c}$ & 85 & 57 & 28 & $6.0 \pm 0.64$ & $12.3 \pm 0.73$ \\
\hline Total & 148 & 104 & 44 & & \\
\hline
\end{tabular}

size. According to this method, no reference structures (such as the cranial base) are used for the superimposition. First, the tracings at 6 and 12 years were superimposed for each center. Next, a cross-sectional figure of all three centers at 6 years or 12 years was made [6-8].

Statistical analysis

Statistical analyses were performed using SPSS 16.0 software (Chicago, IL, USA). Paired $t$ tests were used for calculating systematic differences between the first and second digitization. The reliability between the two measurements was calculated as Pearson's correlation coefficients. In the multiple regression model, center and gender were included as independent variables. Oslo was used as the reference center. The $p$ values for the comparison of increments between the centers were calculated using ANOVA, and the Tukey-B test was used as the post hoc test.

\section{Results}

Sample characteristics for each center are shown in Table 3. The intra-observer duplicate measurement error for all

Table 4 Intra-observer reliability for hard and soft tissue cephalometric measurements

\begin{tabular}{|c|c|c|c|c|c|c|c|c|c|c|}
\hline & \multicolumn{5}{|c|}{ Age 6 years $(n=20)$} & \multicolumn{5}{|c|}{ Age 12 years $(n=20)$} \\
\hline & Reliability & DME & Mean difference & $95 \% \mathrm{CI}$ & $p$ value & Reliability & DME & Mean difference & $95 \% \mathrm{CI}$ & $p$ value \\
\hline \multicolumn{11}{|c|}{ Hard tissue variables } \\
\hline SNA & 0.796 & 2.02 & 0.66 & {$[-0.65-1.96]$} & 0.305 & 0.928 & 0.88 & 0.04 & {$[-0.48-0.57]$} & 0.868 \\
\hline SNB & 0.786 & 1.33 & -0.39 & {$[-1.25-0.47]$} & 0.355 & 0.966 & 0.58 & -0.25 & {$[-0.59-0.10]$} & 0.149 \\
\hline ANB & 0.74 & 1.75 & 1.05 & {$[-0.08-2.17]$} & 0.067 & 0.94 & 0.76 & 0.29 & {$[-0.16-0.75]$} & 0.198 \\
\hline SNPg & 0.706 & 1.52 & -0.37 & {$[-1.35-0.61]$} & 0.435 & 0.962 & 0.66 & -0.34 & {$[-0.73-0.06]$} & 0.089 \\
\hline SN-NL & 0.543 & 2.70 & -0.03 & {$[-1.77-1.71]$} & 0.971 & 0.918 & 1.16 & -0.32 & {$[-1.00-0.38]$} & 0.354 \\
\hline SN-ML & 0.417 & 4.55 & 2.02 & {$[-0.91-4.95]$} & 0.166 & 0.925 & 1.39 & -0.08 & {$[-0.91-0.75]$} & 0.850 \\
\hline NL-ML & 0.457 & 3.30 & -0.43 & {$[-2.60-1.69]$} & 0.679 & 0.926 & 1.31 & 0.24 & {$[-0.54-1.02]$} & 0.531 \\
\hline ILs-SN & 0.497 & 8.90 & -4.07 & {$[-9.80-1.66]$} & 0.154 & 0.967 & 1.78 & 0.99 & {$[-0.07-2.06]$} & 0.065 \\
\hline ILs-NL & 0.583 & 8.03 & -4.10 & {$[-9.27-1.07]$} & 0.114 & 0.967 & 1.85 & 0.64 & {$[-0.47-1.74]$} & 0.244 \\
\hline Interincisal & 0.673 & 9.78 & 3.69 & {$[-2.61-9.99]$} & 0.236 & 0.975 & 1.75 & 0.01 & {$[-1.04-1.05]$} & 0.992 \\
\hline ILI-ML & 0.817 & 2.76 & 0.84 & {$[-0.94-2.61]$} & 0.336 & 0.882 & 1.88 & -1.08 & {$[-2.20-0.04]$} & 0.058 \\
\hline RL-ML* & $0.46^{*}$ & $4.74 *$ & $3.78 *$ & {$[0.73-6.82]^{*}$} & $0.018^{*}$ & 0.815 & 2.84 & -0.91 & {$[-2.60-0.79]$} & 0.280 \\
\hline $\mathrm{NSBa}$ & 0.615 & 2.88 & 1.53 & {$[-0.32-3.39]$} & 0.100 & $0.834^{*}$ & $2.13 *$ & $1.62 *$ & {$[0.34-2.89]^{*}$} & $0.015^{*}$ \\
\hline \multicolumn{11}{|c|}{ Soft tissue variables } \\
\hline Snan & 0.676 & 3.370 & -0.23 & {$[-2.40-1.94]$} & 0.828 & 0.767 & 2.30 & -0.03 & {$[-1.40-1.35]$} & 0.968 \\
\hline Snss & 0.47 & 3.389 & 0.05 & {$[-2.13-2.23]$} & 0.963 & 0.921 & 1.31 & 0.18 & {$[-0.58-0.74]$} & 0.649 \\
\hline Snsm & 0.459 & 2.676 & 0.10 & {$[-1.62-1.82]$} & 0.906 & 0.879 & 1.11 & 0.08 & {$[-0.61-0.96]$} & 0.800 \\
\hline Snpg & 0.409 & 2.593 & 0.02 & {$[-1.65-1.69]$} & 0.984 & 0.895 & 0.99 & 0.13 & {$[-0.46-0.73]$} & 0.650 \\
\hline nanpg & 0.695 & 3.785 & -0.95 & {$[-3.39-1.48]$} & 0.424 & 0.927 & 1.75 & -0.07 & {$[-1.11-0.97]$} & 0.891 \\
\hline nsnpg & 0.757 & 3.753 & 0.96 & {$[-1.46-3.37]$} & 0.418 & 0.947 & 1.77 & 0.18 & {$[-0.87-1.24]$} & 0.725 \\
\hline Nasolabial & 0.721 & 10.72 & -2.66 & {$[-9.56-4.24]$} & 0.431 & 0.887 & 4.97 & 0.22 & {$[-2.75-3.19]$} & 0.880 \\
\hline
\end{tabular}

${ }^{*} p \leq 0.05$, variables that are reaching significance

$D M E$ duplicate measurements error, $C I$ confidence interval 
cephalometric variables at 6 and 12 years of age is presented in Table 4. Significant differences were observed in the variable RL-ML $(p=0.018)$ at 6 years old and NSBa at 12 years old $(p=0.015)$. These variables were excluded from further evaluation in both age groups. For all other variables, the reliability coefficients ranged from 0.409 to 0.817 for the 6-year-old group, and from 0.767 to 0.975 for the 12-year-old group. Hard and soft tissue cephalometric variables for both age groups and the three centers are presented in Table 5.

The increments for all cephalometric variables between 6 and 12 years of age are different among the three centers and are presented in Table 6. For Nijmegen, the increments of the variables SNA, ANB, SN-NL, SN-ML, NL-ML, Snss, and Snpg were significantly different from those of the other two centers $(p=0.041$ to $<0.001)$. SNPg increments were significantly different between Nijmegen and Oslo $(p=0.002)$. The sagittal position of the maxilla diminished during growth for all three centers, which was represented by the hard tissue variable SNA and the soft tissue variable Snss. The variables decreased significantly more at Nijmegen than the other two centers (Fig. 2a, b). The SNA angle also has an effect on the ANB angle, which decreased significantly more in the Nijmegen group than in the other two. The SNPg variable increased significantly more in the Oslo group than the Nijmegen group, and the corresponding soft tissue variable (Snpg) was significantly different in the Nijmegen group compared with the other centers (Fig. 3a, b). The increments for the vertical growth pattern (SN-NL and NL-ML) were significantly different for Nijmegen compared with the other two centers. In the Nijmegen group, SN-NL significantly decreased and NLML increased between 6 and 12 years, and SN-ML was significantly different between the centers $(p=0.041)$. However, none of the differences reached significance in the post hoc test.

The results of the multiple regression model are presented in Table 7 . The cephalometric variables at

Table 5 Hard and soft tissue cephalometric measurements at the three centers

\begin{tabular}{|c|c|c|c|c|c|c|c|c|c|c|c|c|}
\hline & \multicolumn{4}{|c|}{ Center $\mathrm{A}^{\mathrm{a}}\left(n_{A}=37\right)$} & \multicolumn{4}{|c|}{ Center $\mathrm{B}^{\mathrm{b}}\left(n_{B}=26\right)$} & \multicolumn{4}{|c|}{ Center $\mathrm{C}^{\mathrm{c}}\left(n_{C}=85\right)$} \\
\hline & \multicolumn{2}{|l|}{6 years } & \multicolumn{2}{|c|}{12 years } & \multicolumn{2}{|l|}{6 years } & \multicolumn{2}{|c|}{12 years } & \multicolumn{2}{|l|}{6 years } & \multicolumn{2}{|c|}{12 years } \\
\hline & Mean & SD & Mean & SD & Mean & SD & Mean & SD & Mean & SD & Mean & SD \\
\hline \multicolumn{13}{|c|}{ Hard tissue variables } \\
\hline SNA & 85.38 & 4.16 & 79.88 & 3.50 & 85.03 & 5.54 & 77.25 & 4.62 & 84.75 & 4.28 & 80.00 & 3.38 \\
\hline SNB & 75.32 & 3.66 & 75.43 & 3.77 & 72.92 & 4.15 & 72.80 & 4.08 & 74.65 & 3.61 & 75.60 & 3.83 \\
\hline ANB & 10.06 & 3.49 & 4.44 & 2.61 & 12.12 & 3.80 & 4.46 & 3.20 & 10.09 & 3.33 & 4.40 & 3.18 \\
\hline $\mathrm{SNPg}$ & 75.61 & 3.65 & 76.72 & 3.89 & 72.70 & 3.82 & 73.00 & 4.17 & 74.72 & 3.80 & 76.9 & 4.10 \\
\hline SN-NL & 12.90 & 3.78 & 13.13 & 3.55 & 13.02 & 5.86 & 9.21 & 4.53 & 9.62 & 4.50 & 8.27 & 3.62 \\
\hline SN-ML & 36.24 & 4.68 & 36.23 & 4.83 & 39.93 & 5.50 & 39.86 & 5.83 & 35.94 & 5.66 & 34.09 & 6.40 \\
\hline NL-ML & 23.33 & 5.17 & 23.10 & 4.64 & 26.91 & 6.95 & 30.66 & 4.84 & 26.79 & 5.80 & 25.95 & 5.98 \\
\hline ILs-SN & 63.62 & 13.45 & 86.56 & 11.00 & 57.71 & 15.13 & 76.79 & 13.57 & 61.67 & 12.25 & 85.30 & 10.92 \\
\hline ILs-NL & 76.53 & 12.58 & 99.70 & 10.83 & 70.72 & 16.10 & 86.00 & 12.19 & 71.30 & 11.99 & 93.58 & 11.00 \\
\hline Interincisal angle & 172.58 & 14.13 & 148.61 & 11.71 & 177.43 & 18.74 & 154.80 & 15.64 & 175.66 & 16.06 & 151.24 & 13.07 \\
\hline ILi-ML & 87.55 & 9.40 & 88.60 & 7.80 & 84.94 & 7.18 & 88.55 & 7.13 & 86.30 & 7.01 & 93.58 & 11.00 \\
\hline \multicolumn{13}{|c|}{ Soft tissue variables } \\
\hline Snan & 106.63 & 5.17 & 108.96 & 6.12 & 105.84 & 3.40 & 106.20 & 5.56 & 108.85 & 5.63 & 111.29 & 4.93 \\
\hline Snss & 90.62 & 4.50 & 89.01 & 4.86 & 90.86 & 4.68 & 85.20 & 4.73 & 89.44 & 3.92 & 88.18 & 3.91 \\
\hline Snsm & 80.37 & 4.39 & 82.16 & 5.42 & 78.79 & 3.66 & 79.25 & 4.50 & 79.60 & 3.78 & 81.74 & 3.95 \\
\hline Snpg & 81.66 & 4.61 & 83.81 & 5.65 & 80.06 & 3.45 & 80.40 & 4.42 & 81.04 & 3.82 & 83.28 & 4.10 \\
\hline nanpg & 140.02 & 4.90 & 139.13 & 5.34 & 139.50 & 5.08 & 138.47 & 5.20 & 136.51 & 5.75 & 135.01 & 5.56 \\
\hline nsnpg & 159.97 & 6.09 & 167.40 & 6.77 & 157.62 & 7.33 & 167.68 & 7.91 & 161.36 & 7.26 & 168.92 & 7.92 \\
\hline Nasolabial angle & 126.88 & 11.88 & 116.93 & 15.32 & 133.45 & 12.11 & 120.92 & 13.68 & 119.37 & 13.80 & 107.96 & 15.75 \\
\hline
\end{tabular}

All variables are in degrees

$n_{A}, n_{B}, n_{C}$ number of patients per center, $S D$ standard deviation

${ }^{\mathrm{a}}$ Gothenburg

${ }^{\mathrm{b}}$ Nijmegen

${ }^{\mathrm{c}}$ Oslo 
Table 6 Increments of cephalometric values between 6 and 12 years of age
All variables are in degrees. Lowercase letters ( $a$ and $b$ ) denote the difference between the centers. Same letter indicates similarity, whereas a different letter indicates significant difference. $p$ values were calculated with ANOVA, using Tukey$\mathrm{B}$ as the post hoc test

$n_{A}, n_{B}, n_{C}$ number of patients per center

${ }^{\mathrm{a}}$ Gothenburg

${ }^{\mathrm{b}}$ Nijmegen

${ }^{\mathrm{c}}$ Oslo

\begin{tabular}{|c|c|c|c|c|c|c|c|}
\hline & \multicolumn{2}{|c|}{ Center $\mathrm{A}^{\mathrm{a}}(n A=37)$} & \multicolumn{2}{|c|}{ Center $\mathrm{B}^{\mathrm{b}}(n B=26)$} & \multicolumn{3}{|c|}{ Center $\mathrm{C}^{\mathrm{c}}(n C=85)$} \\
\hline & Mean & SD & Mean & $\mathrm{SD}$ & Mean & SD & $p$ value \\
\hline \multicolumn{8}{|c|}{ Hard tissue variables } \\
\hline SNA & $-5.50 \mathrm{a}$ & 2.75 & $-7.78 \mathrm{~b}$ & 4.57 & $-4.75 \mathrm{a}$ & 2.99 & $<0.001$ \\
\hline SNB & 0.12 & 1.83 & -0.12 & 2.70 & 0.95 & 2.50 & 0.065 \\
\hline ANB & $-5.62 \mathrm{a}$ & 2.76 & $-7.66 \mathrm{~b}$ & 4.45 & $-5.70 \mathrm{a}$ & 2.93 & 0.018 \\
\hline SNPg & $1.12 \mathrm{a}, \mathrm{b}$ & 1.82 & $0.30 \mathrm{~b}$ & 2.60 & $2.22 \mathrm{a}$ & 2.72 & 0.002 \\
\hline SN-NL & $0.23 \mathrm{a}$ & 3.68 & $-3.80 \mathrm{~b}$ & 35.36 & $-1.35 \mathrm{a}$ & 4.62 & 0.003 \\
\hline SN-ML & -0.008 & 2.97 & -0.06 & 2.68 & -1.85 & 5.07 & 0.041 \\
\hline NL-ML & $-0.24 \mathrm{a}$ & 4.02 & $3.75 \mathrm{~b}$ & 6.05 & $-0.84 \mathrm{a}$ & 5.77 & 0.001 \\
\hline ILs-SN & 22.93 & 13.64 & 19.08 & 17.70 & 23.64 & 16.92 & 0.459 \\
\hline ILs-NL & 23.17 & 14.34 & 15.27 & 18.35 & 22.27 & 16.66 & 0.122 \\
\hline Interincisal angle & -23.97 & 14.68 & -22.63 & 19.90 & -24.42 & 19.42 & 0.911 \\
\hline ILi-ML & 1.046 & 14.34 & 3.61 & 7.05 & 3.00 & 7.64 & 0.289 \\
\hline \multicolumn{8}{|c|}{ Soft tissue variables } \\
\hline Snan & 2.33 & 4.03 & 0.36 & 5.47 & 2.44 & 5.78 & 0.212 \\
\hline Snss & $-1.61 \mathrm{a}$ & 3.04 & $-5.67 \mathrm{~b}$ & 3.89 & $-1.26 \mathrm{a}$ & 3.25 & $<0.001$ \\
\hline Snsm & 1.78 & 3.02 & 0.46 & 2.76 & 2.14 & 3.35 & 0.066 \\
\hline Snpg & $2.16 \mathrm{a}$ & 3.28 & $0.34 \mathrm{~b}$ & 2.61 & $2.24 \mathrm{a}$ & 3.16 & 0.021 \\
\hline nanpg & -0.89 & 4.08 & -1.03 & 6.67 & -1.50 & 5.26 & 0.814 \\
\hline nsnpg & 7.42 & 4.14 & 10.06 & 7.21 & 7.56 & 5.92 & 0.130 \\
\hline Nasolabial angle & -9.95 & 12.97 & -12.53 & 12.58 & -11.41 & 16.17 & 0.783 \\
\hline
\end{tabular}

12 years were the dependent variables, and the cephalometric variables at 6 years, gender, and center (Gothenburg or Nijmegen) were the independent variables. Oslo is the reference category center. All cephalometric variables except the ones related to the upper incisors could be explained by the cephalometric variables at 6 years of age. Gender did not play a significant role in predicting the values of the cephalometric variables at 12 years of age. A center effect was present for Gothenburg for SNPg, Snpg, and SN-NL, which were predictive values for the 12-year results. The center effect for Nijmegen, which is marked in bold in Table 7, was found for the prediction of a number of cephalometric variables (SNA, SNB, SNPg, SN-ML, and NL-ML) at 12 years of age.

For every cephalometric variable, a prediction model can be extracted using the following equation, which estimates, for example, the SNA angle at age 12 to be:

$$
\begin{aligned}
\mathrm{SNA}_{12} & =32.27+0.564 \mathrm{SNA}_{6}-0.29-0.48 \text { Gothenburg } \\
& -2.94 \text { Nijmegen }
\end{aligned}
$$

For instance a girl (boy=0 and girl=1), from Gothenburg (Nijmegen $=0$ and Gothenburg=1), with an SNA angle of $88^{\circ}$ at 6 years is estimated to have a SNA angle at 12 years of: $32.27+0.564 \times 88-0.29-0.48=81.13^{\circ}$.

The results of superimposition using the generalized Procrustes analysis of the 6- and 12-year-old group means are shown in Fig. $4 \mathrm{a}-\mathrm{c}$. Figure 5 visualizes the superimpositions of the mean tracings of all three centers at 6 (Fig. 5a) and 12 years (Fig. 5b).

\section{Discussion}

An intercenter comparison allows access to adequate samples for investigating clinical outcomes and international variations in treatment outcomes and growth adaptation [9]. However, intercenter studies cannot eliminate susceptibility or proficiency bias as the patients are drawn from different populations and the surgeons are inevitably different, but the patients from the three centers in the present study were treated by a limited number of surgeons according to a strictly defined and consistent protocol (see Table 2). Nevertheless, intercenter studies are not easy to perform. The variability in record taking and treatment protocol, even within the same center, as well as many co-factors such as clinician skill, proficiency, and the possibility of adapting a treatment procedure to the expected prognosis, make intercenter studies difficult. Even if the research evidence for retrospective longitudinal studies is considered to be rather weak, it has the advantage of recruiting consecutive cases for consistent evaluation $[10,11]$. For the present study, we were able to include 148 patients with CBCLP who were followed 

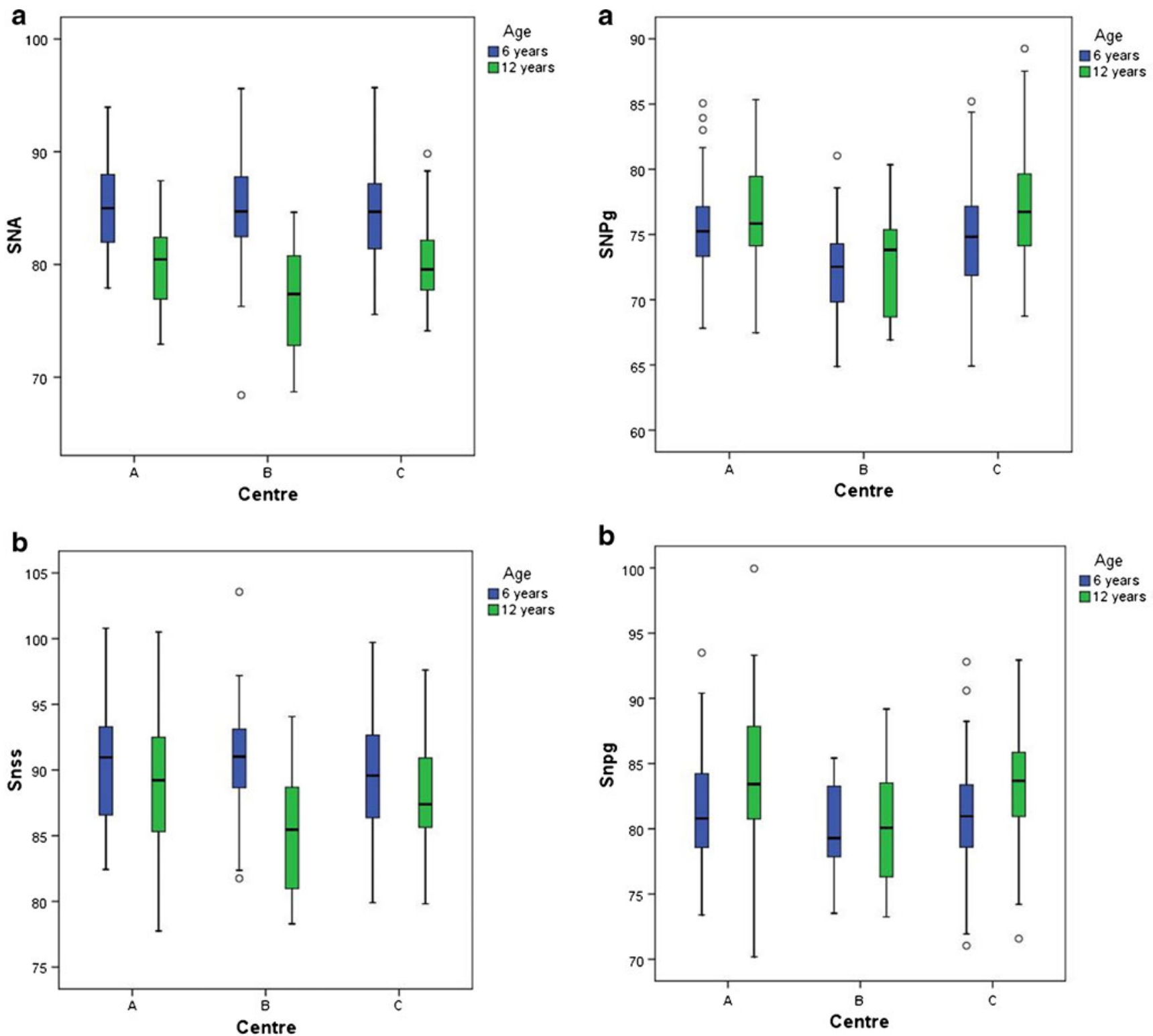

Fig. 2 Box plot distribution of a angles SNA and $\mathbf{b}$ Snss (in degrees) at 6 (blue) and 12 (green) years of age. (Centers: $A$ Gothenburg, $B$ Nijmegen, and $C$ Oslo)

longitudinally over a 6-year period, which is the largest sample reported in the literature to date. Only a few studies with very small samples cover the same age period longitudinally (Table 1).

In order to reach a consensus on data collection for further research purposes, the Eurocleft project has specified the ages for recording cleft lip and palate patients. Cephalometric radiographs were recommended at the age of 10 years [12]. In the present study, the CBCLP patients were born before 1996 in order to have radiographs at the two target ages and is the reason why our age groups were not in accordance with the Eurocleft recommendations published later [12].

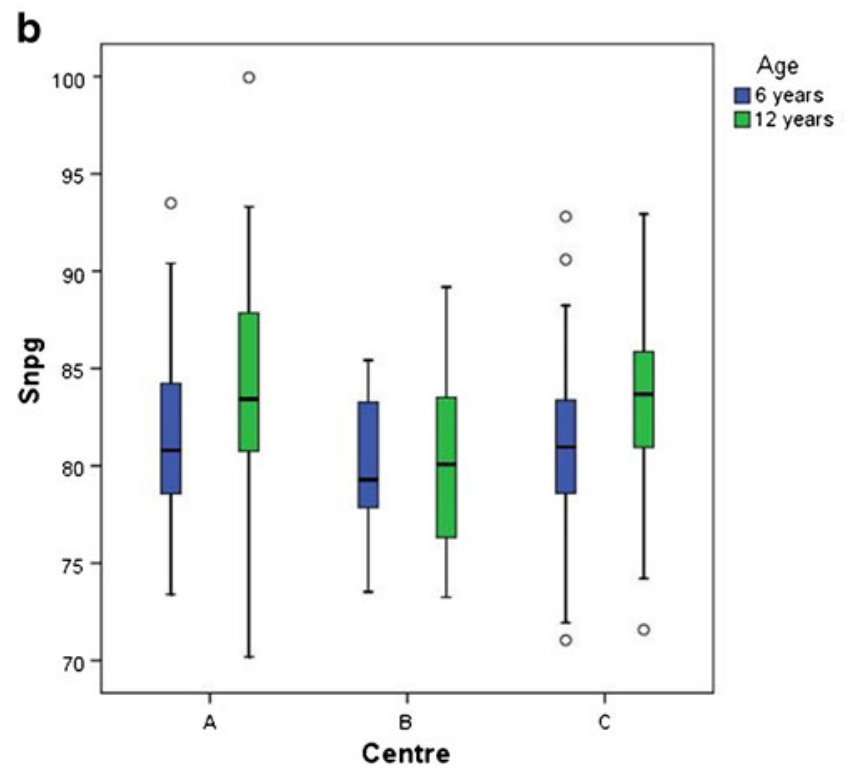

Fig. 3 Box plot distribution of a angles SNPg and b Snpg (in degrees) at 6 (blue) and 12 (green) years of age. (Centers: $A$ Gothenburg, $B$ Nijmegen, and $C$ Oslo)

Three-dimensional cephalometry is the latest tool, but 2D cephalometric analysis is still the classic tool for describing facial growth and development in patients with cleft lip and palate. Because of concerns about the radiation dose of multislice or cone-beam computer tomography, it will probably continue to be the evaluation tool for longitudinal studies on facial growth and treatment outcome. However, in addition to the fact that 2D cephalometry is a two-dimensional representation of three-dimensional structures, cephalometric measurements have an inherent method error that varies depending on the radiographic projection, measuring system, type of landmark, and observer. Differences in the magnitude of the measurement error are caused by the precision of landmark 


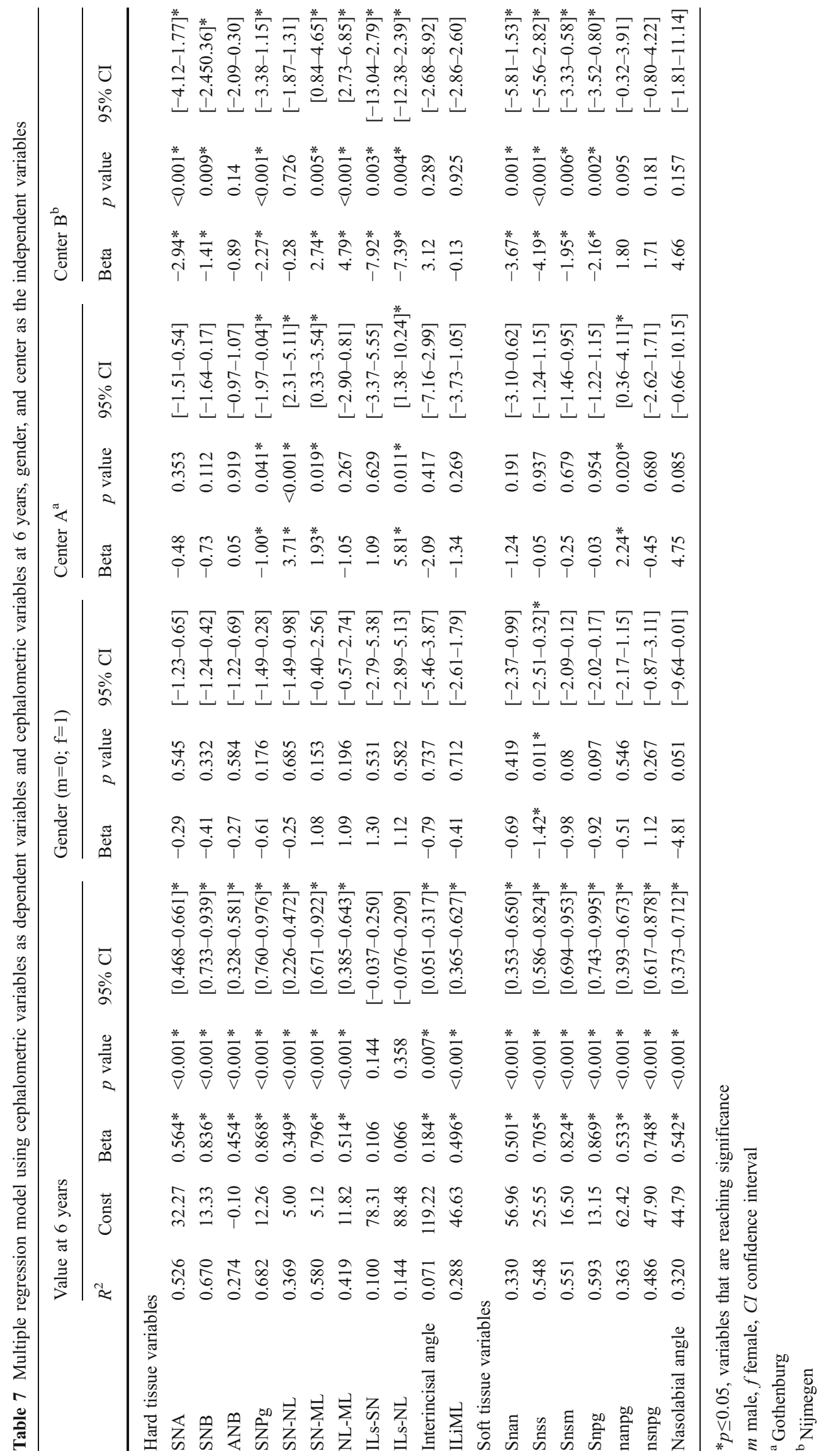


Fig. 4 Mean tracings illustrating the craniofacial morphology in CBCLP at 6 (blue) and 12 (red) years of age. a Center $A$ Gothenburg, b Center $B$ Nijmegen, c Center $C$ Oslo

\section{a}
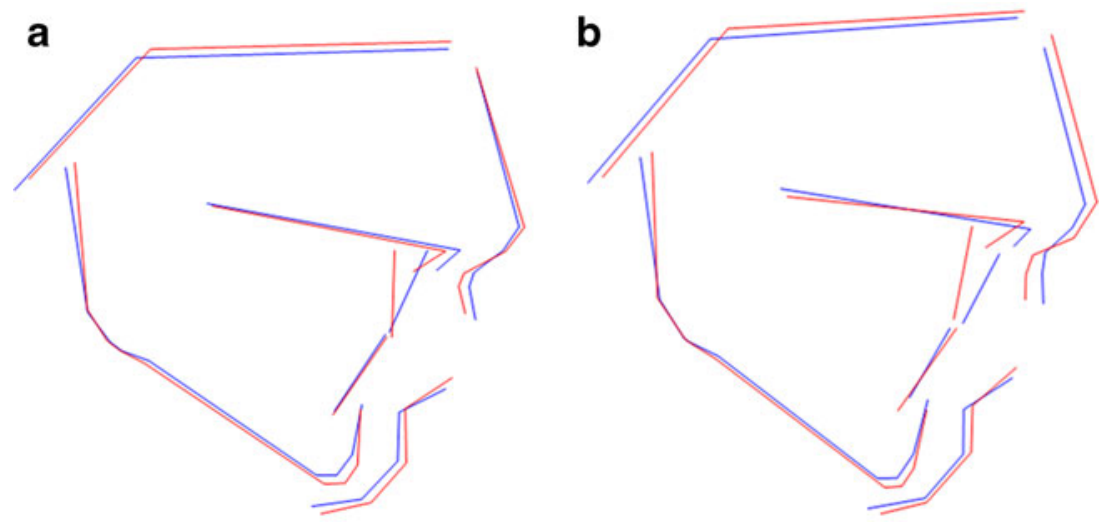

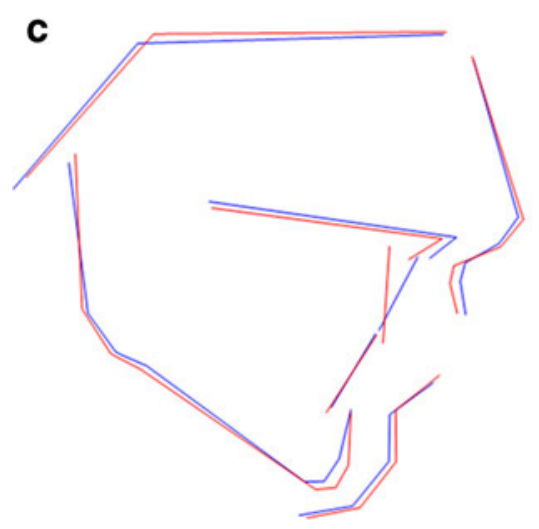

definition and the amount of noise from adjacent structures. In young patients with cleft lip and palate, the identification of cephalometric landmarks is even more difficult due to abnormal anatomy, especially for the localization of the landmarks point $\mathrm{A}$, anterior nasal spine, and posterior nasal spine [13]. As described by Hotz and Gnoinski [14], point A is difficult to locate in young individuals because of the tooth germs molding the anterior contour of the maxilla. The most difficult age for examining radiographs in patients with a cleft is the period before shedding of the incisors, as all of the above-mentioned problems occur in this period of time. In our study, the intra-observer measurement error showed a systematic difference for one of 20 variables in the 6-year group and one in the 12-year-old group (see Table 4).

At 6 years of age, all patients (at all centers) with CBCLP showed a large SNA angle with retroclined upper incisors. This finding should not be interpreted as a prognathism of the entire maxilla, but the large SNA angle is the result of a forward positioning of the premaxilla in bilateral cleft lip and palate. Cephalometric findings at an even earlier age than examined in our study have shown an extremely protruding premaxilla with a short maxilla of reduced posterior height, a short mandible, and bimaxillary retrognathia with a more vertical facial growth pattern [15]. The protrusion of the premaxilla in the 6-year olds from all
Fig. 5 Mean tracings illustrating the craniofacial morphology in CBCLP from all three centers at $\mathbf{a} 6$ and b 12 years (crosssectional figures). Centers $A$ Gothenburg (red), $B$ Nijmegen (blue), and C Oslo (green)
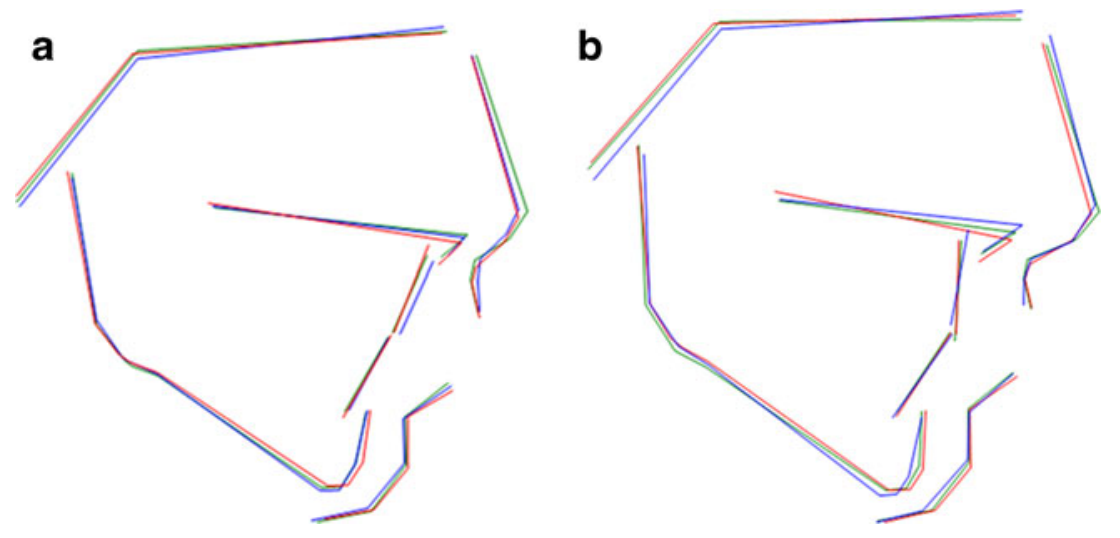
three centers was similar to the recently published results of a well-documented longitudinal study (from age 5 until the end of growth) on the treatment outcome of Zurich's treatment protocol in 5-year olds [16].

In the following 6-year period, the protrusion of the premaxilla diminished similarly for all three groups but occurred most in the Nijmegen group (see Table 6 and Fig. 2a, b). This pattern was also seen for the ANB angle and the corresponding soft tissue variable Snss. This change probably reflects the change brought about by the osteotomy of the premaxilla, which was performed in all patients at Nijmegen with the bone grafting procedure at a mean age of 9 years and 9 months. The direct effect of this operation is a better sagittal position of the premaxilla and an improved inclination and vertical position of the upper incisors, as well as reconstruction of the alveolar process to a normal height and width to create optimal conditions for canine eruption $[17,18]$. However, whether the premaxillary surgery will result in impaired forward growth of the maxilla in the long run remains to be seen. In a preliminary cephalometric study that included seven patients from the present study, patients were followed longitudinally from 6 to 20 years of age for their final facial growth [4]. At the age of 20 , osteotomy of the premaxilla at a mean age of 13 years and 3 months was not found to have been detrimental to facial growth. Comparable results were found by Padwa et al. [18] and Geraedts et al. [19], who showed that a protrusive premaxilla can be positioned after the age of 6 to 8 years without deleterious effects on midfacial growth. However, the final outcome for the present sample remains to be investigated when growth has ceased.

In the Nijmegen patients, NS-NL decreased and NL-ML increased, indicating a counter clockwise rotation of the premaxilla. This pattern differs from that of the other centers and can probably be attributed to the surgical repositioning of the premaxilla in the CBCLP patients at Nijmegen before the age of 12 .

The regression analysis (Table 7) showed that most of the hard tissue variables and all soft tissue variables at 12 years are explained by the relevant cephalometric values at 6 years of age. The $R$ square numbers show that you can explain approximately $50 \%$ of the variability in 12-year values. The only variables that are not predictive are the ones related to the maxillary incisors, which could be expected as patients differ with respect to their dental developmental stage when the cephalograms were made. Gender did not play a significant role in explaining the cephalometric outcome at 12 years of age.

Many components that are difficult to identify are involved in the final outcome of cleft lip and palate patients. In addition to the growth variability between individuals and racial groups, drawing the line for the ideal treatment protocol is difficult as the treatment protocols of the three centers have primary differences in the early management of clefts, infant orthopedics, the type of lip repair (one-stage or two-stage approach), early versus late hard palate closure, and premaxillary osteotomy at the age of 9 years (Table 2). The developmental heterogeneity of individuals between centers is also an important factor. In a comparative study of cephalometric values among five centers, Nijmegen had significantly more Class II skeletal patients compared with all other centers [20]. In the present study, we also noticed that the Dutch children had a significantly more retrusive mandibular growth pattern than the Scandinavian children.

\section{Conclusions}

Even though the three cleft centers followed different treatment protocols, the craniofacial morphology of their patients with CBCLP was not very different until the age of 12. However, the growth pattern differed, especially with respect to maxillary and upper incisor variables. The premaxillary osteotomy performed around 10 years of age in Nijmegen seems to inhibit sagittal and vertical maxillary development. Further evaluation of the group until growth has ceased is needed to solve the controversy about the long-term effect of premaxillary osteotomy.

Acknowledgments The authors would like to thank Dr. Rania Nada and Dr. Hans Dijkman for their computational support.

Conflict of interest Demetrios Halazonetis has a financial interest in the Viewbox software used for cephalometric analysis.

Open Access This article is distributed under the terms of the Creative Commons Attribution Noncommercial License which permits any noncommercial use, distribution, and reproduction in any medium, provided the original author(s) and source are credited.

\section{References}

1. Sivertsen A, Wilcox A, Johnson GE, Abyholm F, Vindenes HA, Lie RT (2008) Prevalence of major anatomic variations in oral clefts. Plast Reconstr Surg 121:587-595

2. Trotman CA, Ross RB (1993) Craniofacial growth in bilateral cleft lip and palate: ages six years to adulthood. Cleft Palate Craniofac J 30:261-273

3. Silvera QA, Ishii K, Arai T, Morita S, Ono K, Iida A, Hanada K, Takagi R (2003) Long-term results of the two-stage palatoplasty/ Hotz' plate approach for complete bilateral cleft lip, alveolus and palate patients. J Craniomaxillofac Surg 31:215-227

4. Heidbüchel KL, Kuijpers-Jagtman AM, Freihofer HP (1994) Facial growth in patients with bilateral cleft lip and palate: a cephalometric study. Cleft Palate Craniofac J 31:210-216

5. Semb G (1991) A study of facial growth in patients with bilateral cleft lip and palate treated by the Oslo clp team. Cleft Palate Craniofac J 28:22-39 
6. Halazonetis DJ (2004) Morphometrics for cephalometric diagnosis. Am J Orthod Dentofacial Orthop 125:571-581

7. Bookstein FL (1991) Morphometric tools for landmark data: geometry and biology. Cambridge University Press, Cambridge

8. Dryden IL, Mardia KV (1998) Statistical shape analysis. Wiley, Chichester

9. Shaw WC (2004) Global strategies to reduce the health care burden of craniofacial anomalies: report of who meetings on international collaborative research on craniofacial anomalies. Cleft Palate Craniofac J 41:238-243

10. Shaw WC, Asher-McDade C, Brattstrom V, Dahl E, McWilliam J, Molsted K, Plint DA, Prahl-Andersen B, Semb G, The RP (1992) A six-centre international study of treatment outcome in patients with clefts of the lip and palate: Part 1. Principles and study design. Cleft Palate Craniofac J 29:393-397

11. Shaw WC, Dahl E, Asher-McDade C, Brattstrom V, Mars M, McWilliam J, Molsted K, Plint DA, Prahl-Andersen B, Roberts C et al (1992) A six-centre international study of treatment outcome in patients with clefts of the lip and palate: Part 5. General discussion and conclusions. Cleft Palate Craniofac J 29:413-418

12. Shaw WC, Semb G, Nelson P, Brattström V, Mølsted K, PrahlAndersen B (2000) The eurocleft project 1996-2000. Ios Press, Amsterdam

13. Bongaarts CA, van't Hof MA, Prahl-Andersen B, KuijpersJagtman AM (2008) Identification of cephalometric landmarks in unilateral cleft lip and palate patients: are there alternatives for point A, ANS, and PNS? Cleft Palate Craniofac J 45:81-86

14. Hotz M, Gnoinski W (1976) Comprehensive care of cleft lip and palate children at Zurich university: a preliminary report. Am J Orthod 70:481-504

15. Hermann NV, Darvann TA, Jensen BL, Dahl E, Bolund S, Kreiborg S (2004) Early craniofacial morphology and growth in children with bilateral complete cleft lip and palate. Cleft Palate Craniofac J 41:424-438

16. Gnoinski WM, Rutz G (2009) A longitudinal cephalometric study from age 5 to 18 years on individuals with complete bilateral cleft lip and palate. J Craniofac Surg 20(Suppl 2):1672-1682

17. Hayward JR (1983) Management of the premaxilla in bilateral clefts. J Oral Maxillofac Surg 41:518-524

18. Padwa BL, Sonis A, Bagheri S, Mulliken JB (1999) Children with repaired bilateral cleft lip/palate: effect of age at premaxillary osteotomy on facial growth. Plast Reconstr Surg 104:1261-1269

19. Geraedts CT, Borstlap WA, Groenewoud JM, Borstlap-Engels VM, Stoelinga PJ (2007) Long-term evaluation of bilateral cleft lip and palate patients after early secondary closure and premaxilla repositioning. Int J Oral Maxillofac Surg 36:788-796

20. Trenouth MJ, Laitung G, Naftel AJ (1999) Differences in cephalometric reference values between five centres: relevance to the eurocleft study. Br J Oral Maxillofac Surg 37:19-24 